Research Article

\title{
A Comparative Study of $\mathrm{CO}_{2}$ Emission Forecasting in the Gulf Countries Using Autoregressive Integrated Moving Average, Artificial Neural Network, and Holt-Winters Exponential Smoothing Models
}

\author{
Teg Alam $\mathbb{D}$ and Ali AlArjani \\ Department of Industrial Engineering, College of Engineering, Prince Sattam Bin Abdulaziz University, \\ Al Kharj 16273, Saudi Arabia \\ Correspondence should be addressed to Teg Alam; t.alam@psau.edu.sa
}

Received 18 September 2021; Revised 1 November 2021; Accepted 8 November 2021; Published 23 December 2021

Academic Editor: Antonio Donateo

Copyright ( $) 2021$ Teg Alam and Ali AlArjani. This is an open access article distributed under the Creative Commons Attribution License, which permits unrestricted use, distribution, and reproduction in any medium, provided the original work is properly cited.

\begin{abstract}
Forecasting is the process of making predictions based on past and present data, with the most common method being trend analysis. Forecasting models are becoming increasingly crucial in uncovering the intricate linkages between large amounts of imprecise data and uncontrollable variables. The main purpose of this article is to compare $\mathrm{CO}_{2}$ emission forecasts in Gulf countries. In this study, the autoregressive integrated moving average (ARIMA), artificial neural network (ANN), and holtWinters exponential smoothing (HWES) forecasting models are used to anticipate $\mathrm{CO}_{2}$ emissions in the Gulf countries on an annual basis. This study attempts to predict time series data on $\mathrm{CO}_{2}$ emissions in the Gulf countries using statistical tools. The current analysis relied on secondary data gathered from the United States Energy Information Administration (EIA). The study's findings show that the ARIMA $(1,1,1)$, Holt-Winters exponential smoothing, ARIMA $(1,1,2)$, and ARIMA $(2,1,2)$ models do not outperform the artificial neural network model in estimating $\mathrm{CO}_{2}$ emissions in the Gulf countries. This study gives information on the current state of $\mathrm{CO}_{2}$ emission forecasts. This study will aid the researcher's understanding of $\mathrm{CO}_{2}$ emissions forecasts. In addition, government agencies can use the findings of this study to develop strategic plans.
\end{abstract}

\section{Introduction}

This research aims to forecast $\mathrm{CO}_{2}$ emissions in Gulf countries. Gulf countries have long dominated the oil and gas industry. They produce around 35 and 25 percent of the world's natural gas and crude oil, respectively, and are its major crude oil producers. $\mathrm{CO}_{2}$ is the most significant greenhouse gas emitted by human activity. Carbon dioxide exists in the atmosphere naturally as part of the Earth's carbon cycle (the natural circulation of carbon among the atmosphere, oceans, soil, plants, and animals) [1].

According to Saudi government plans, multiple measures have been taken towards predicting the country's future. ARIMA $(1,0,0)$, ARIMA $(0,1,1)$, ARIMA $(1,1,2)$, and ANN suitable models were used for predicting the total revenue and expenditure of Saudi Arabia [2]. The expected growth of $\mathrm{CO}_{2}$ emissions of China has suddenly increased throughout the selected period of the study [3]. The regression analyses had been employed for 25 countries, and the statistical analyses indicated that eleven countries had a significant trend [4]. The gray prediction method was used to forecast the future $\mathrm{CO}_{2}$ emissions for the period of 2010-2012 in Taiwan, and the study showed that $\mathrm{CO}_{2}$ emissions would increase over the next three years [5]. The $\mathrm{CO}_{2}$ data of 1999-2009 had been used to predict the future trend by using gray method (GM) [6].

Recently, many studies have combined ARIMA, HoltWinters exponential smoothing, and ANN methods for $\mathrm{CO}_{2}$ emission predictions. Prediction of $\mathrm{CO}_{2}$ emissions based on the time series data has been analyzed, compared, and 
interpreted using ARIMA and other forecasting models [7-11]. The forecasting models are significantly important methods applied in numerous areas of scientific studies. The researchers have used various prediction models in their studies for the prediction of $\mathrm{CO}_{2}$ emissions and the other regions [12-19].

Here are some other forecasting prediction approaches. A proposed hybrid model is unique in that it combines the advantages of ARIMA and ANNs in modeling linear and nonlinear behaviors in the data set. Furthermore, the computational experience illustrates the new combination model's effectiveness in obtaining more accurate forecasting than earlier methodologies [20]. A hybrid technique that integrates both ARIMA and ANN models is used to exploit the various characteristics of ARIMA and ANN models in linear and nonlinear modeling. And, the results show that merging the models can be a helpful method for enhancing the forecast accuracy of each model alone [21]. The proposed hybrid ARIMA-ANN model was compared to individual ARIMA and ANN models and different current hybrid ARIMA-ANN models using simulated and experimental data sets such as sunspot data and energy prices, as well as stock market data. According to the results from all of these data sets, the proposed hybrid model exhibits higher prediction accuracy for both one-step-ahead and multistageahead forecasts [22]. Two additive hybrid approaches and five multiplicative hybrid methods were investigated to estimate the monthly retail and wholesale prices of regularly used vegetable crops, notably tomato, onion, and potato [23]. The R package Forecast-TB was created to assess the accuracy of various forecasting approaches as a function of time series data set features. In addition, Forecast-TB illustrated raw time series dataset to evaluate forecasting comparison analysis as a function of dataset attributes [24]. The improved chicken swarm optimization (ICSO) algorithm, also known as ICSO-SVM, is presented to optimize SVM parameters. Finally, the novel hybrid model is used to forecast $\mathrm{CO}_{2}$ emissions from residential energy use in Shanghai, China. The simulation results show that the ICSOSVM model surpasses the other models when it comes to forecasting accuracy. Furthermore, the ICSO-SVM model's thorough examination of influencing elements and remarkable performance in predicting $\mathrm{CO}_{2}$ emissions can provide relevant researchers and policymakers with more breakthrough points for residential $\mathrm{CO}_{2}$ emission reduction [25].

Furthermore, two proposed time series decomposition methods are developed for short-term forecasting of the $\mathrm{CO}_{2}$ emissions of electricity consumption for five European countries [26]. In addition, a hybrid approach based on artificial neural networks and an agent-based architecture has been described for forecasting carbon dioxide $\left(\mathrm{CO}_{2}\right)$ emissions from various energy sources in the city of Annaba using actual data. The development is based on Algerian gas and electricity data provided by the national energy company [27].

For forecasting $\mathrm{CO}_{2}$ emissions in the Gulf countries, the autoregressive integrated moving average (ARIMA), HoltWinters exponential smoothing, and artificial neural network (ANN) forecasting models were proposed in this study. The ARIMA, Holt-Winters, and ANN forecasting techniques are the most widely used among the various forecasting methods chosen for this study.

The observations of $\mathrm{CO}_{2}$ emissions ranging from 1960 to 2014 of the Gulf countries were chosen to predict $\mathrm{CO}_{2}$ emissions. The findings of the ARIMA, ANN, and HoltWinters exponential smoothing models were examined to find the best match in this study. This comparison identified the best fit for predicting $\mathrm{CO}_{2}$ emissions.

\section{Materials and Methods}

Research methods and materials are summarized in the following. The data used for the ARIMA, ANN, and HWES models were primarily collected from the publicly available source. Minitab version 17 and Zaitun Time Series software have been used to run the models, respectively.

2.1. Data. $\mathrm{CO}_{2}$ emissions data of Gulf countries were collected from the US EIA between 1960 and 2014. The data were measured in metric tons per capita.

2.2. Auto Regressive Integrated Moving Average (ARIMA). ARIMA models are capable of representing both stationary and nonstationary time series data. Remember that stationary processes have a fixed range of variation. At the level, nonstationary methods have no natural constant mean. ARIMA $(p, d, q)$ models provide an approach to time series forecasting and describe the data's autocorrelations. ARIMA consists of autoregressive $(p)$, different $(d)$, and moving average $(q)$. The proposed ARIMA models used in this study are as follows:

ARIMA $(1,1,1)$ :

$$
\widehat{Y}=\varnothing_{0}+Y_{t-1}+\varnothing_{1}\left(Y_{t-1}-Y_{t-2}\right)-\omega_{1} \varepsilon_{t-1} .
$$

ARIMA (1,1,2):

$$
\widehat{Y}=\varnothing_{0}+Y_{t-1}+\varnothing_{1}\left(Y_{t-1}-Y_{t-2}\right)-\omega_{1} \varepsilon_{t-1}-\omega_{2} \varepsilon_{t-2} .
$$

$$
\begin{aligned}
& \operatorname{ARIMA}(2,1,2) \text { : } \\
& \begin{aligned}
\widehat{Y}= & \varnothing_{0}+Y_{t-1}+\varnothing_{1}\left(Y_{t-1}-Y_{t-2}\right)+\varnothing_{2}\left(Y_{t-2}-Y_{t-3}\right) \\
& -\omega_{1} \varepsilon_{t-1}-\omega_{2} \varepsilon_{t-2} .
\end{aligned}
\end{aligned}
$$

Here, we have the following:

$\widehat{Y}$ is the predicted value in the time series

$Y_{t-1}$ and $Y_{t-2}$ are the response variables at time lags $t-1$ and $t-2$

$\varepsilon_{t-1}$ and $\varepsilon_{t-2}$ are the errors in previous time periods $\varnothing_{0}, \varnothing_{1}, \varnothing_{2}, \omega_{1}$, and $\omega_{2}$ are the coefficients to be estimated $[28,29]$ 
ARIMA models are the most comprehensive time series for forecasting applications. This paper uses ARIMA models to anticipate $\mathrm{CO}_{2}$ emissions in Gulf countries and compares them to other models.

2.3. Artificial Neural Network (ANN). Time series forecasting has significantly benefited from the use of neural networks. As a result, the use of neural networks to forecast time series is gaining popularity.

ANNs have solved many forecasting problems. Because neural networks are generally complex, they are beneficial for capturing the complex underlying relationship in many real-world problems. In addition, neural networks are potentially more versatile forecasting applications because they can detect linear and nonlinear structures in a problem. Several academics have investigated and reported on the ability of neural networks to describe linear time series ([2,30] and others). This study used an artificial neural network which is known as a neural network. It consists of an input layer of neurons or nodes, one or two hidden neurons, and a final layer of output neurons. A neuron is an information-processing unit that is fundamental to the operation of a neural network. The artificial neurons we use to build our neural networks are genuinely primitive compared to those found in the brain $[28,29]$. The proposed ANN model is as follows:

$$
¥=\varphi\left(\sum_{j=1}^{n} x_{j}+\rightrightarrows\right) .
$$

Here, we have the following:

$¥$ denotes the output signal

$x_{n}$ indicates the input signals

$\#_{n}$ denotes the synaptic weights of the neuron

$\varphi$ denotes the activation function

3 denotes the bias

Figure 1 represents the general model of ANN.

This study applies the artificial neural network (ANN) technique to forecast $\mathrm{CO}_{2}$ emissions in Gulf countries.

2.4. Holt-Winters Exponential Smoothing. This paper also uses the Holt-Winters method to predict $\mathrm{CO}_{2}$ emissions. This method is applicable if the time series data have trend and seasonal effects. In addition to the alpha and beta smoothing factors, a new parameter is added called gamma $(\gamma)$ that controls the influence's seasonal component. The equations used in this model are as follows.

The exponentially smoothed series or level estimate is given as

$$
L_{t}=\alpha\left(\frac{Y_{T}}{S_{T-M}}\right)+(1-\alpha)\left(L_{t-1}-T_{t-1}\right) .
$$

The trend estimate is given as

$$
T_{t}=\beta\left(L_{t}-L_{t-1}\right)+(1-\beta) T_{t-1} .
$$

The seasonality estimate is developed as

$$
S_{t}=\gamma\left(\frac{Y_{T}}{L_{t}}\right)+(1-\gamma) S_{t-s} .
$$

The forecast for $m$ periods into the future is written as

$$
F_{t+m}=\left(L_{t}+m T_{t}\right) S_{t-s+m}
$$

Here, we have the following:

$Y_{T}$ is the new observation

$L_{T}$ is the current level estimate of series

$L_{T-1}$ is the previously smoothed level

$\alpha$ is the smoothing constant for the level

$\beta$ is the smoothing constant for trend estimate

$T_{t}$ is the current trend estimate

$T_{t-1}$ is the previously smoothed trend

$\gamma$ is the smoothing constant for seasonality estimate

$S_{t}$ is the seasonal component estimate

$S_{t-s}$ is the previous seasonal component

$m$ is the number of seasons in a year

$s$ is the length of seasonality (number of periods in the season)

$t$ is the time period

$0 \leq \alpha \leq 1 ; 0 \leq \beta \leq 1 ;$ and $\leq \gamma \leq 1[28,29]$

This study also compares the Holt-Winters exponential smoothing model to other models in order to predict $\mathrm{CO}_{2}$ emissions in the Gulf countries.

2.5. Accuracy Measures of the Forecast Models. In this study, we analyzed the different errors of forecast models for comparing to each other, which are mean absolute error (MAE), mean squared error (MSE), root mean square error (RMSE), and mean absolute percentage error (MAPE) $[28,29]$.

2.5.1. Mean Absolute Error (MAE). The mean absolute error (MAE) measures the accuracy of fitted time series values. MAE expresses accuracy in the same units as the data, which helps conceptualize the amount of error and is calculated by the following formula:

$$
\begin{aligned}
\text { MAE }= & \frac{1}{\text { number of observations }(n)} \\
& \cdot \sum_{\text {time }(t)=1}^{n} \mid \text { response variable }_{t}-\overline{\text { predicted value }}_{t} \mid
\end{aligned}
$$

2.5.2. Mean Squared Error (MSE). The mean squared error (MSE) is a more sensitive measure of a substantial forecast error than MAE, and the following formula estimates it: 


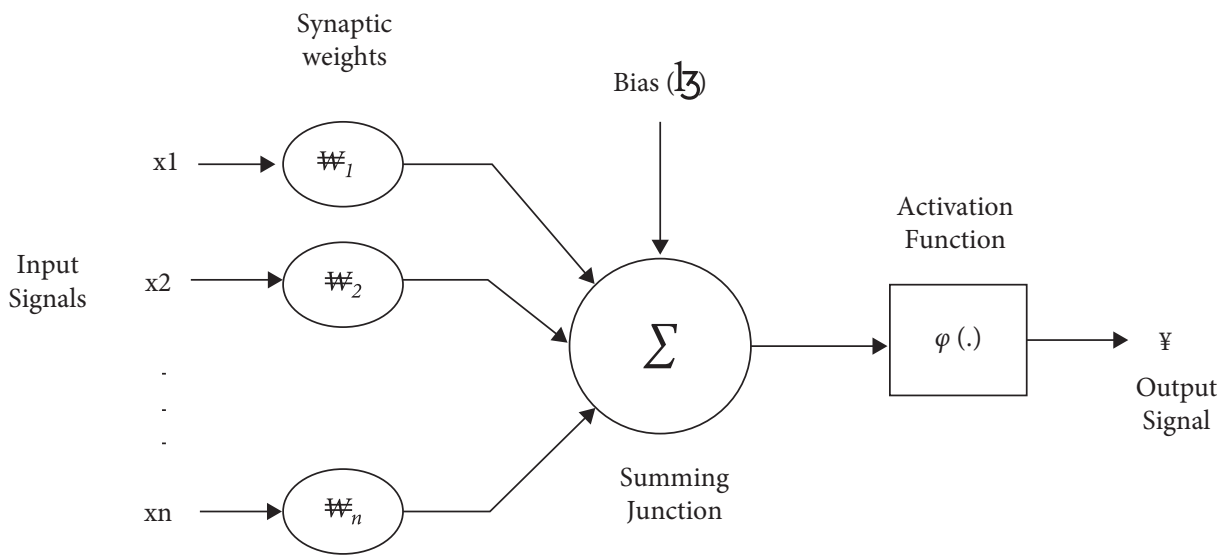

Figure 1: General model of a neuron.

$\mathrm{MSE}=\frac{1}{n} \sum_{t=1}^{n}\left(\text { response variable }_{t}-\overline{\text { predicted value }}_{t}\right)^{2}$.

2.5.3. Root Mean Square Error (RMSE). The root mean square error (RMSE), like the MSE, penalizes significant errors but has the same units as the forecast, so its magnitude is easily interpreted.

$$
\mathrm{RMSE}=\sqrt{\mathrm{MSE}} \text {. }
$$

2.5.4. Mean Absolute Percentage Error (MAPE). The mean absolute percentage error (MAPE) measures the accuracy of fitted time series values. MAPE expresses accuracy as a percentage, and the following formula estimates it:

$$
\mathrm{MAPE}=\frac{1}{n} \sum_{t=1}^{n} \frac{\mid \text { response variable }_{t}-\overline{\text { predicted value }}_{t} \mid}{\text { response variable }_{t}} .
$$

After the analysis for errors, we compare the accuracy measures of the forecast models. Less MAPE and less RMSE often are the best way to define the best forecast.

Following that, we present the outcomes of the ARIMA, ANN, and HWES model implementations.

\section{Results and Discussion}

3.1. Predicted Value of $\mathrm{CO}_{2}$ Emissions (Metric Tons per Capita) Using the Various Forecasting Models. The proposed forecasting models will assist GCC nations in determining the best fit model to predict $\mathrm{CO}_{2}$ emissions.

It is evident from Table 1 and Figure 2, the $\mathrm{CO}_{2}$ emissions of the GCC countries will continue increasing over the years except for Kuwait. Table 1 shows that the model ARIMA $(1,1,1)$ is the best fit for predicting $\mathrm{CO}_{2}$ emissions of Oman, Saudi Arabia, Bahrain, Kuwait, UAE, and Qatar according to their sequence of accuracy measures.
From Table 2 and Figure 3, we conclude that the $\mathrm{CO}_{2}$ emissions of the GCC countries will continue increasing over the years except for Kuwait. Table 2 shows that the model ARIMA $(1,1,2)$ is the best fit for predicting $\mathrm{CO}_{2}$ emissions in Oman, Saudi Arabia, Bahrain, Kuwait, $\mathrm{UAE}$, and Qatar based on the sequence of accuracy measures.

It is evident from Table 3 and Figure 4 , the $\mathrm{CO}_{2}$ emissions of the GCC countries will continue increasing over the years, except for Kuwait and Qatar. Table 3 shows that the model ARIMA $(2,1,2)$ is the best fit for predicting $\mathrm{CO}_{2}$ emissions of the kingdom of Saudi Arabia, Oman, Bahrain, Kuwait, and Qatar according to their sequence of accuracy measures.

From Table 4 and Figure 5, we conclude that the $\mathrm{CO}_{2}$ emissions of the GCC countries will continue increasing and decreasing over the years except for Kuwait. It is evident from Table 4 that the model ANN is the best fit for predicting $\mathrm{CO}_{2}$ emissions of Oman, Saudi Arabia, Bahrain, UAE, Kuwait, and Qatar according to their sequence of accuracy measures.

From Table 5 and Figure 6, we can say that the $\mathrm{CO}_{2}$ emissions of KSA will continue increasing and decreasing over the years. Also, it seems that the $\mathrm{CO}_{2}$ emissions of the UAE, Kuwait, Bahrain, and Qatar will continue declining over the years except for Oman. It is evident from Table 5 that the model of Holt-Winters exponential smoothing is the best fit for the prediction of $\mathrm{CO}_{2}$ emissions of Oman according to their accuracy measures.

3.2. Comparison of the Best Predicted $\mathrm{CO}_{2}$ Emissions Values for 2025. The best prediction for the year 2025 is shown in Table 6 and Figure 7. As a consequence, ANN is the best model for the Gulf Countries based on the accuracy measures. It is not an easy task to create a neural network model for a time series forecasting assessment. As several software packages exist to assist users in building a neural network model, forecasters must understand many important issues surrounding the model construction. For example, the ANN software package does not need to produce the correct result 
TABLE 1: Predicted value of $\mathrm{CO}_{2}$ emissions (metric tons per capita) using the ARIMA $(1,1,1)$ model and accuracy measures.

\begin{tabular}{|c|c|c|c|c|c|c|}
\hline Year & KSA & UAE & KWT & BHR & QAT & OMAN \\
\hline 2015 & 19.8132 & 22.032 & 25.6859 & 23.8404 & 45.4081 & 15.336 \\
\hline 2016 & 20.178 & 23.073 & 25.6503 & 24.1938 & 46.6756 & 15.6805 \\
\hline 2017 & 20.5361 & 23.176 & 25.5865 & 24.5455 & 47.7162 & 15.9687 \\
\hline 2018 & 20.8884 & 23.73 & 25.5289 & 24.8972 & 48.5749 & 16.2729 \\
\hline 2019 & 21.2355 & 24.067 & 25.4699 & 25.2489 & 49.2879 & 16.5726 \\
\hline 2020 & 21.5783 & 24.509 & 25.4113 & 25.6005 & 49.8844 & 16.8736 \\
\hline 2021 & 21.9172 & 24.9 & 25.3526 & 25.9522 & 50.3873 & 17.1742 \\
\hline 2022 & 22.2528 & 25.316 & 25.2938 & 26.3039 & 50.8154 & 17.475 \\
\hline 2023 & 22.5855 & 25.719 & 25.2351 & 26.6555 & 51.1836 & 17.7757 \\
\hline 2024 & 22.9156 & 26.129 & 25.1764 & 27.0072 & 51.5037 & 18.0764 \\
\hline 2025 & 23.2436 & 26.536 & 25.1177 & 27.3589 & 51.7854 & 18.3771 \\
\hline MSE & 2.728546 & 191.1273 & 39.47481363 & 7.50587707 & 199.110449 & 1.581776118 \\
\hline RMSE & 1.651831 & 13.82488 & 6.282898506 & 2.739685579 & 14.1106502 & 1.257686812 \\
\hline
\end{tabular}

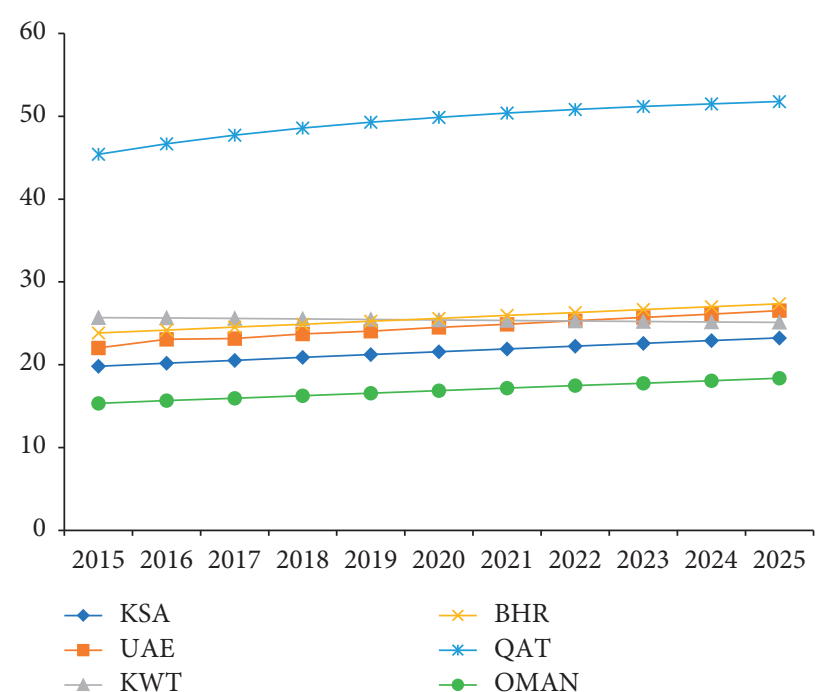

FIgURE 2: Predicted value of $\mathrm{CO}_{2}$ emissions (metric tons per capita) using the ARIMA $(1,1,1)$ model.

TABle 2: Predicted value of $\mathrm{CO}_{2}$ emissions (metric tons per capita) using the ARIMA $(1,1,2)$ model and accuracy measures.

\begin{tabular}{lcccccc}
\hline Year & KSA & UAE & KWT & BHR & QAT & OMAN \\
\hline 2015 & 19.8274 & 22.032 & 25.2979 & 23.0702 & 48.9564 & 15.2469 \\
2016 & 20.2132 & 23.057 & 25.0196 & 24.1298 & 24.0314 & 53.6255 \\
2017 & 20.5898 & 23.136 & 24.7665 & 24.6683 & 55.1167 \\
2018 & 20.9584 & 23.718 & 24.5337 & 24.8383 & 56.2585 & 15.6726 \\
2019 & 21.3201 & 24.032 & 24.317 & 25.3048 & 57.1533 \\
2020 & 21.6757 & 24.489 & 24.1133 & 25.583 & 57.8735 \\
2021 & 22.026 & 24.87 & 23.92 & 25.9808 & 58.4702 & 16.4249 \\
2022 & 22.3717 & 25.291 & 23.735 & 26.3026 & 58.9796 & 17.1038 \\
2023 & 22.7135 & 25.691 & 23.5567 & 26.6726 & 59.4272 & 17.7285 \\
2024 & 23.0517 & 26.102 & 23.3837 & 27.0121 & 59.8312 \\
2025 & 23.387 & 26.508 & 23.2149 & 6.53011983 & 174.7189806 & 18.0617 \\
MSE & 2.69729 & 191.0923 & 36.73398116 & 2.555409914 & 13.21813075 \\
RMSE & 1.64234 & 13.82361 & 6.06085647 & & 1.4375 .683 \\
\hline
\end{tabular}




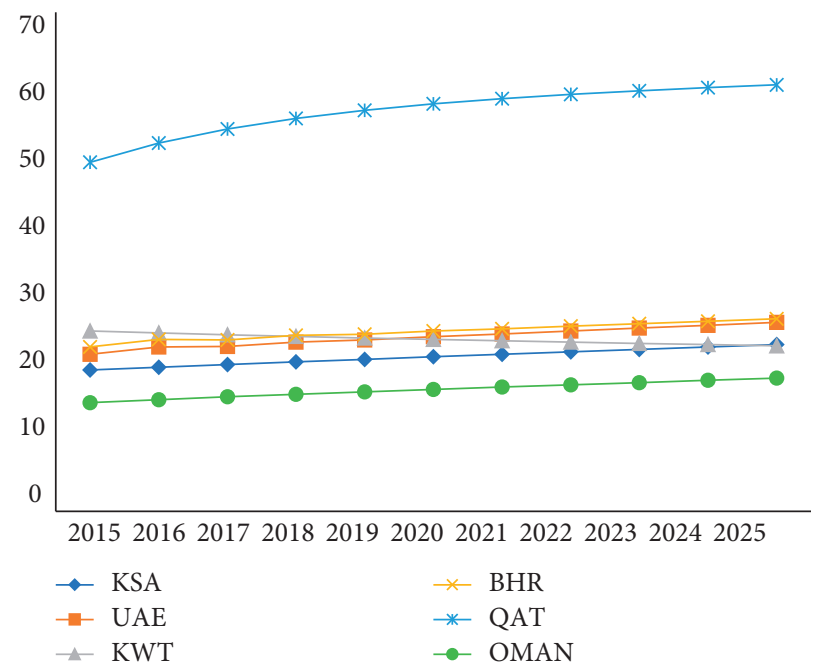

FIgure 3: Predicted value of $\mathrm{CO}_{2}$ emissions (metric tons per capita) using the ARIMA $(1,1,2)$ model.

TABle 3: Predicted value of $\mathrm{CO}_{2}$ emissions (metric tons per capita) using the ARIMA $(2,1,2)$ model and accuracy measures.

\begin{tabular}{lcccccc}
\hline Year & KSA & UAE & KWT & BHR & QAT & OMAN \\
\hline 2015 & 19.2517 & 22.1399 & 25.3724 & 23.1818 & 40.0646 & 35.45 \\
2016 & 20.4422 & 23.0162 & 25.0809 & 24.4201 & 24.0725 & 32.4005 \\
2017 & 20.2464 & 22.9346 & 24.8022 & 24.8493 & 32.5155 & 16.284 \\
2018 & 21.3706 & 23.329 & 24.5477 & 25.014 & 35.8467 & 16.3999 \\
2019 & 21.1754 & 23.4278 & 24.3113 & 25.418 & 40.8942 & 17.557 \\
2020 & 22.2428 & 23.654 & 24.0898 & 25.7906 & 45.3509 & 17.4425 \\
2021 & 22.0535 & 23.7826 & 23.8803 & 26.11 & 47.2266 & 17.637 \\
2022 & 23.0715 & 23.9392 & 23.6807 & 26.4967 & 45.8029 & 17.8727 \\
2023 & 22.8924 & 24.0589 & 23.4891 & 26.8318 & 41.9622 & 18.2753 \\
2024 & 23.8669 & 24.1797 & 23.3039 & 27.1969 & 37.7401 & 18.6406 \\
2025 & 23.7007 & 24.2835 & 23.124 & 6.342618621 & 197.9863674 & 1.3809833 \\
MSE & 2.48489 & 181.5921 & 36.79337864 & 2.518455602 & 14.07076286 & 1.175140438 \\
RMSE & 1.576353 & 13.47561 & 6.065754582 & &
\end{tabular}

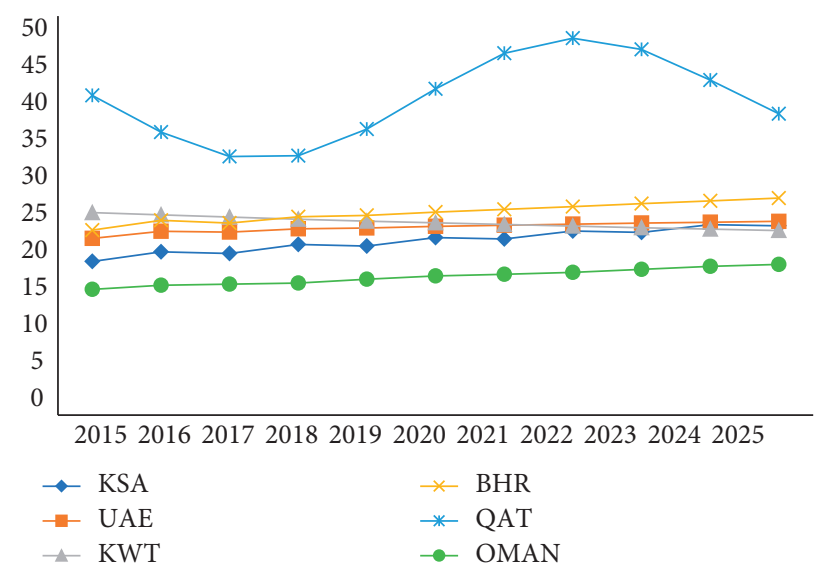

FIgURE 4: Predicted value of $\mathrm{CO}_{2}$ emissions (metric tons per capita) using the ARIMA $(2,1,2)$ model. 
TABle 4: Predicted value of $\mathrm{CO}_{2}$ emissions (metric tons per capita) using the ANN model and accuracy measures.

\begin{tabular}{lcccccc}
\hline Year & KSA & UAE & KWT & BHR & QAT & OMAN \\
\hline 2015 & 17.7764 & 23.6796 & 25.3525 & 20.7706 & 42.0368 \\
2016 & 18.292 & 24.8476 & 23.213 & 25.0854 & 42.5176 & 16.169 \\
2017 & 17.77 & 25.348 & 22.6426 & 25.4424 & 42.5139 \\
2018 & 18.4168 & 26.1558 & 21.9359 & 26.0121 & 47.1656 \\
2019 & 17.7574 & 26.3692 & 20.8619 & 26.655 & 49.4236 & 16.1421 \\
2020 & 18.2973 & 26.5869 & 20.1502 & 24.4962 & 51.9579 & 16.1208 \\
2021 & 17.6336 & 26.7628 & 19.7581 & 24.3246 & 52.2961 & 16.3724 \\
2022 & 18.4311 & 26.2901 & 19.2751 & 25.3826 & 53.5767 & 16.1978 \\
2023 & 17.7389 & 26.0693 & 18.9593 & 24.0357 & 52.4733 & 16.1845 \\
2024 & 18.4094 & 25.403 & 18.9986 & 23.0032 & 54.3419 & 16.2966 \\
2025 & 17.8752 & 25.0183 & 18.9484 & 24.6834 & 52.9035 \\
MSE & 2.063634 & 13.94389 & 14.8509483 & 2.92500569 & 24.1817259 & 0.75614137 \\
RMSE & 1.436536 & 3.734152 & 3.85369282 & 1.7102648 & 4.91749183 \\
\hline
\end{tabular}

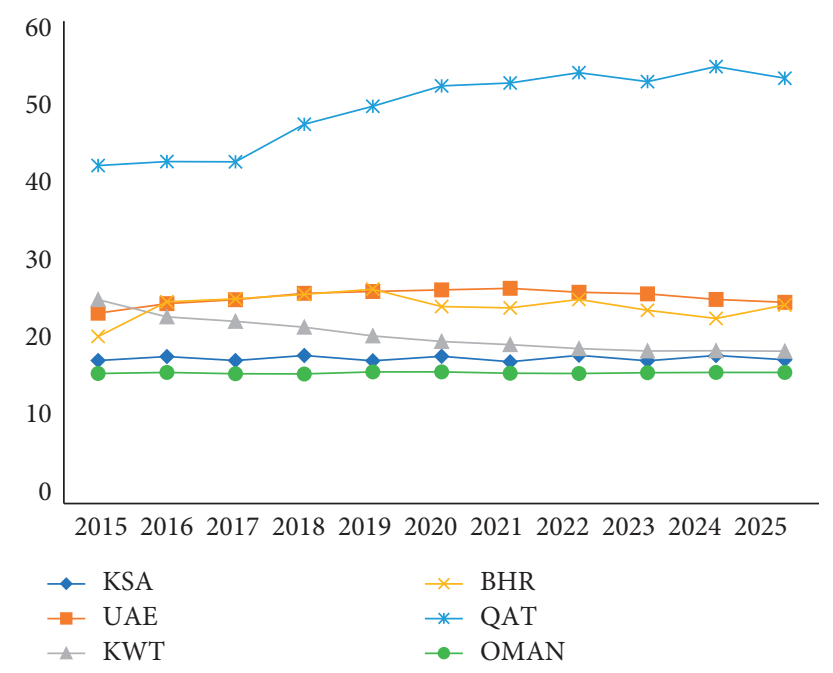

FIgURE 5: Predicted value of $\mathrm{CO}_{2}$ emissions (metric tons per capita) using the ANN model.

TABle 5: Predicted value of $\mathrm{CO}_{2}$ emissions (metric tons per capita) using the Holt-Winters exponential smoothing model and accuracy measures.

\begin{tabular}{|c|c|c|c|c|c|c|}
\hline Year & KSA & UAE & KWT & BHR & QAT & OMAN \\
\hline 2015 & 18.9619 & 18.3657 & 28.8636 & 22.8149 & 36.9647 & 17.7822 \\
\hline 2016 & 20.3868 & 18.7049 & 28.8068 & 22.4036 & 36.5989 & 17.8181 \\
\hline 2017 & 19.6537 & 17.3906 & 28.5948 & 22.6495 & 33.7156 & 18.6483 \\
\hline 2018 & 21.1172 & 17.6846 & 28.5373 & 22.2406 & 33.2341 & 18.6652 \\
\hline 2019 & 20.3454 & 16.4155 & 28.326 & 22.4841 & 30.4665 & 19.5143 \\
\hline 2020 & 21.8477 & 16.6644 & 28.2677 & 22.0776 & 29.8692 & 19.5124 \\
\hline 2021 & 21.0372 & 15.4404 & 28.0571 & 22.3187 & 27.2173 & 20.3804 \\
\hline 2022 & 22.5781 & 15.6442 & 27.9982 & 21.9146 & 26.5044 & 20.3595 \\
\hline 2023 & 21.729 & 14.4653 & 27.7883 & 22.1533 & 23.9682 & 21.2464 \\
\hline 2024 & 23.3086 & 14.624 & 27.7287 & 21.7516 & 23.1395 & 21.2067 \\
\hline 2025 & 22.4208 & 13.4902 & 27.5195 & 21.9879 & 20.7191 & 22.1125 \\
\hline MSE & 5.300806 & 457.0809 & 129.2720698 & 38.3314634 & 496.415161 & 3.796661954 \\
\hline RMSE & 2.302348 & 21.37945 & 11.36978759 & 6.19124086 & 22.2803761 & 1.94850249 \\
\hline
\end{tabular}




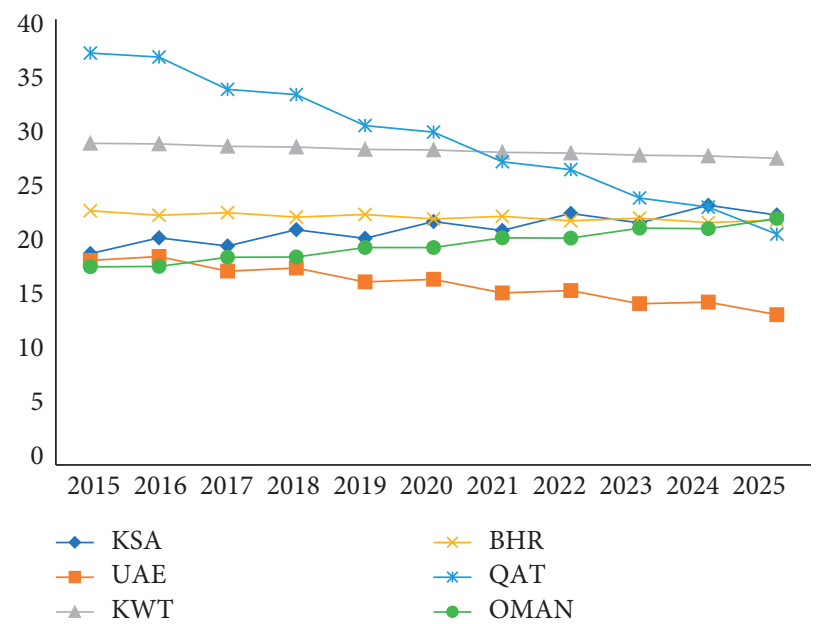

FIgURE 6: Predicted value of $\mathrm{CO}_{2}$ emissions (metric tons per capita) using the Holt-Winters exponential smoothing model.

TABLE 6: Best predicted value of $\mathrm{CO}_{2}$ emissions for the year 2025.

\begin{tabular}{lcccr}
\hline \multirow{2}{*}{ Countries } & \multicolumn{4}{c}{ Best prediction of $\mathrm{CO}_{2}$ emissions (metric tons per capita) for the year 2025 } \\
& ARIMA $(1,1,1)$ & ARIMA $(1,1,2)$ & ARIMA $(2,1,2)$ & ANN \\
\hline KSA & 23.2436 & 23.387 & 23.7007 & 17.8752 \\
UAE & 26.536 & 26.508 & 24.2835 & 25.0183 \\
KWT & 25.1177 & 23.2149 & 23.124 & 18.9484 \\
BHR & 27.3589 & 27.0121 & 27.1969 & 24.6834 \\
QAT & 51.7854 & 59.8312 & 37.7401 & 52.9035 \\
OMAN & 18.3771 & 18.683 & 18.8833 & 27.5195 \\
\hline
\end{tabular}

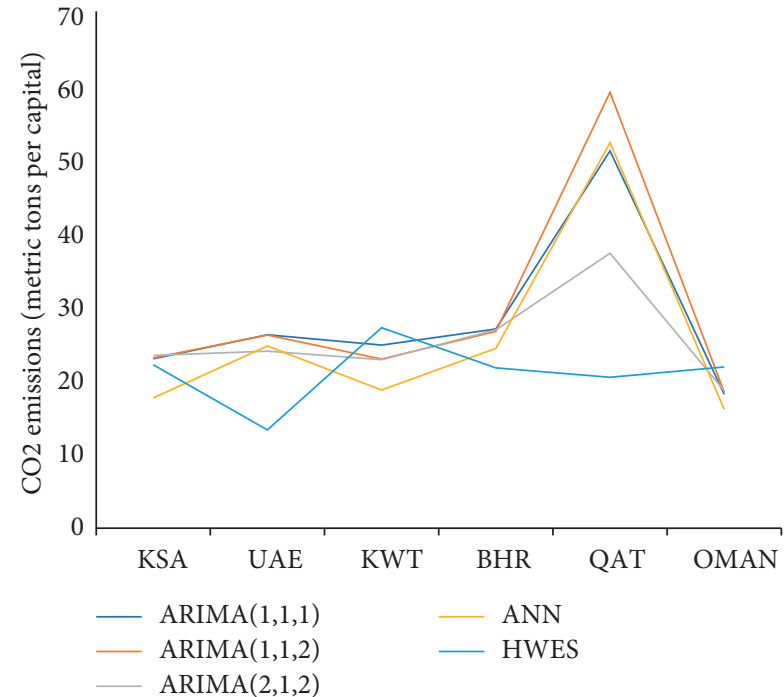

FIgURE 7: Best predicted values of $\mathrm{CO}_{2}$ emissions for the year 2025.

for every data set. Since ANN software solves complex problems, it is often seen that ARIMA and HWES are suitable for linear time series compared to the ANN. In this study, ANN has proved to be a good model among the other models.

\section{Conclusions and Recommendations}

The main aim of the study is to predict the $\mathrm{CO}_{2}$ emissions in Gulf countries. Autoregressive integrated moving average, Holt-Winters exponential smoothing, and artificial neural network models are the finest models with any changing pattern to predict the amount of any time series data. They are appropriate for at least fifty observations. In light of the accuracy measures, we concluded that the ANN model is the best fit for the Gulf countries in 2025.

The predicted value of $\mathrm{CO}_{2}$ emissions in the Gulf countries for the year 2025 will be fluctuating compared to 2014. The outcomes of the research indicate that the researcher should concentrate on the models ANN, ARIMA $(1,1,1)$, Holt-Winters exponential smoothing, ARIMA $(1,1,2)$, and ARIMA $(2,1,2)$ for predicting time series data regarding $\mathrm{CO}_{2}$ emissions in the Gulf countries. In addition, the scope of this study is to identify the adequacy of the ANN model for this type of data set. Furthermore, researchers should focus on the kind of data because ANN requires an extensive data set, whereas ARIMA requires at least 50 observational data sets.

ANN, ARIMA, and HWES are the most commonly utilized forecasting models. Therefore, based on the data set, we applied these methods. Furthermore, the critical focus of future research will be on identifying the area and using 
support vector machine (SVM) regression models and polynomial surface fit (PSF) models to predict the right field of study. Besides, in the subsequent study, we will compare forecasting models using the R package and Python.

\section{Data Availability}

Previously reported financial data were used to support this study and are available at (https://www.eia.gov/). These prior studies (and datasets) are cited at a relevant place within the text as reference [31].

\section{Conflicts of Interest}

The authors declare no conflicts of interest.

\section{References}

[1] https://www.epa.gov/ghgemissions/overview-greenhouse-gas es\#CO2, 2020.

[2] T. Alam, "Predicting revenues and expenditures using artificial neural network and autoregressive integrated moving average," in Proceedings of the 2020 International Conference on Computing and Information Technology (ICCIT-1441), pp. 1-4, Tabuk, Saudi Arabia, September 2020.

[3] M. Auffhammer and R. T. Carson, "Forecasting the path of China's $\mathrm{CO}_{2}$ emissions using province-level information," Journal of Environmental Economics and Management, vol. 55, no. 3, pp. 229-247, 2008.

[4] A. Ç. Köne and T. Büke, "Forecasting of $\mathrm{CO}_{2}$ emissions from fuel combustion using trend analysis," Renewable and Sustainable Energy Reviews, vol. 14, no. 9, pp. 2906-2915, 2010.

[5] C.-S. Lin, F.-M. Liou, and C.-P. Huang, "Grey forecasting model for $\mathrm{CO}_{2}$ emissions: a Taiwan study," Applied Energy, vol. 88, no. 11, pp. 3816-3820, 2011.

[6] H. Yilmaz and M. Yilmaz, "Forecasting $\mathrm{CO}_{2}$ emissions for Turkey by using the grey prediction method," Sigma: Linguistique Anglaise, Linguistique Generale, vol. 31, pp. 141-148, 2013.

[7] L. Abdullah and H. M. Pauzi, "Forecasting carbon dioxide emissions: a decade review," Jurnal Teknologi (Sciences \& Engineering), vol. 75, no. 1, pp. 67-82, 2015.

[8] S. Jiang, C. Yang, J. Guo, and Z. Ding, "ARIMA forecasting of China's coal consumption, price and investment by 2030," Energy Sources, Part B: Economics, Planning and Policy, vol. 13, no. 3, pp. 190-195, 2018.

[9] F. Jiang, X. Yang, and S. Li, "Comparison of forecasting India's energy demand using an MGM, ARIMA model, MGM-ARIMA model, and BP neural network model," Sustainability, vol. 10, no. 7, Article ID 2225, 2018.

[10] A. Jothikannan and M. Dineshkumar, "Modeling and forecasting climatology $\mathrm{CO}_{2}$ in seasonal ARIMA process," Aayvagam an International Journal of Multidisciplinary Research, vol. 5, no. 2, pp. 39-47, 2017.

[11] T. Nyoni and W. G. Bonga, "Prediction of $\mathrm{CO}_{2}$ emissions in India using arima models," DRJ-Journal of Economics \& Finance, vol. 4, no. 2, pp. 01-10, 2019.

[12] T. Alam, "Forecasting exports and imports through artificial neural network and autoregressive integrated moving average," Decision Science Letters, vol. 8, no. 3, pp. 249-260, 2019.

[13] Y. M. Awel, "Forecasting GDP growth: application of autoregressive integrated moving average model," Empirical Economic Review, vol. 1, no. 2, pp. 1-16, 2018.
[14] N. Ersen, İ. Akyüz, and B. C.. Bayram, "The forecasting of the exports and imports of paper and paper products of Turkey using Box-Jenkins's method," Eurasian Journal of Forest Science, vol. 7, no. 1, pp. 54-65, 2019.

[15] S. M. Hosseini, A. Saifoddin, R. Shirmohammadi, and A. Aslani, "Forecasting of $\mathrm{CO}_{2}$ emissions in Iran based on time series and regression analysis," Energy Report, vol. 5, pp. 619-631, 2019.

[16] P. Kitworawut and V. Rungreunganun, "Corn price modeling and forecasting using box-jenkins model," Applied Science and Engineering Progress, vol. 12, no. 4, pp. 277-285, 2019.

[17] F. A. Olabemiwo, B. S. Tawabini, F. Patel, T. A. Oyehan, M. Khaled, and T. Laoui, "Forecasting $\mathrm{CO}_{2}$ emissions in the Persian gulf states," Global Journal of Environmental Science and Management, vol. 3, no. 1, pp. 1-10, 2017.

[18] P. Sen, M. Roy, and P. Pal, "Application of ARIMA for forecasting energy consumption and GHG emission: a case study of an Indian pig iron manufacturing organization," Energy, vol. 116, pp. 1031-1038, 2016.

[19] J. D. Urrutia, A. M. Abdul, and J. B. E. Atienza, "Forecasting Philippines imports and exports using Bayesian artificial neural network and autoregressive integrated moving average," AIP Conference Proceedings, vol. 2192, no. 1, Article ID 090015, 2019.

[20] L. Wang, H. Zou, J. Su, L. Li, and S. Chaudhry, "An ARIMAANN hybrid model for time series forecasting," Systems Research and Behavioral Science, vol. 30, no. 3, pp. 244-259, 2013.

[21] G. P. Zhang, "Time series forecasting using a hybrid ARIMA and neural network model," Neurocomputing, vol. 50, pp. 159-175, 2003.

[22] C. N. Babu and B. E. Reddy, "A moving-average filter based hybrid ARIMA-ANN model for forecasting time series data," Applied Soft Computing, vol. 23, pp. 27-38, 2014.

[23] S. K. Purohit, S. Panigrahi, P. K. Sethy, and S. K. Behera, "Time series forecasting of price of agricultural products using hybrid methods," Applied Artificial Intelligence, pp. 1-19, 2021.

[24] N. D. Bokde, Z. M. Yaseen, and G. B. Andersen, "Forecast TBan $\mathrm{R}$ package as a test-bench for time series forecasting-application of wind speed and solar radiation modeling," Energies, vol. 13, no. 10, Article ID 2578, 2020.

[25] L. Wen and Y. Cao, "Influencing factors analysis and forecasting of residential energy-related $\mathrm{CO}_{2}$ emissions utilizing optimized support vector machine," Journal of Cleaner Production, vol. 250, Article ID 119492, 2020.

[26] N. D. Bokde, B. Tranberg, and G. B. Andresen, "Short-term $\mathrm{CO}_{2}$ emissions forecasting based on decomposition approaches and its impact on electricity market scheduling," Applied Energy, vol. 281, Article ID 116061, 2021.

[27] S. E. Bouziane, M. T. Khadir, and J. Dugdale, "A collaborative predictive multi-agent system for forecasting carbon emissions related to energy consumption," Multiagent and Grid Systems, vol. 17, no. 1, pp. 39-58, 2021.

[28] J. E. Hanke and D. W. Wichern, Business Forecasting, Pearson Prentice Hall, Hoboken, NJ, USA, 8th edition, 2005.

[29] R. S. Russell and B. W. Taylor, Operations Management, Pearson Prentice Hall, Hoboken, NJ, USA, 4th edition, 2005.

[30] G. P. Zhang, "An investigation of neural networks for linear time-series forecasting," Computers \& Operations Research, vol. 28, pp. 1183-1202, 2001.

[31] US EIA (Energy Information Administration), 2021, https:// www.eia.gov/. 